\title{
The predictive role of personality traits on academic performance of medical students: The mediating role of self-efficacy
}

\author{
Ali Asghar Hayat ${ }^{1}$, Naeimeh Kohoulat ${ }^{2}$, Mitra Amini ${ }^{1}$, Seyed Ali Akbar Faghihi*1 (D) \\ Received: 14 May 2019 \\ Published: 11 Jul 2020
}

\begin{abstract}
Background: Determining the variables influencing students' academic performance is one of the main preoccupations in medical colleges. Therefore, this study examined the effect of the Big Five personality traits on medical students' academic performance, considering the mediating role of self-efficacy.

Methods: We applied a cross sectional research design using a PLS-SEM approach. A total of 249 medical students participated in this study. Two valid and reliable questionnaires, including Big Five Inventory (BFI-10) and New General Self Efficacy (GSE) were used. Data were analyzed using both SPSS 18 and PLS2 software.

Results: The validity and reliability of the questionnaires were confirmed by confirmatory factor analysis. The results revealed that openness $(\beta=0.16, p<0.001)$, conscientiousness $(\beta=0.22, p<0.001)$, agreeableness $(\beta=0.19, p<0.001)$, and self-efficacy $(\beta=0.24$, $\mathrm{p}<0.001)$ had a significant positive and direct effect on academic performance. Neuroticism $(\beta=-0.21, \mathrm{p}<0.001)$ had a significant negative and direct effect on academic performance. Also, openness $(\beta=0.47, \mathrm{p}<0.001)$ and conscientiousness $(\beta=0.33, \mathrm{p}<0.001)$ had a direct positive effect on self-efficacy. Neuroticism $(\beta=-0.15, \mathrm{p}<0.001)$ had a direct negative effect on self-efficacy. Moreover, the results showed an indirect positive effect of conscientiousness $(\beta=0.08, \mathrm{p}<0.001)$ and openness $(\beta=0.11, \mathrm{p}<0.001)$ on academic performance through self-efficacy. In addition, the results showed that neuroticism $(\beta=-0.03, p<0.001)$ had an indirect negative effect on academic performance through self-efficacy.

Conclusion: This study discovered the relationships between personality traits, self-efficacy, and academic performance of medical students. The results showed that individual differences in personality traits directly and indirectly play an essential role, through selfefficacy, in contributing to the students' academic performance.
\end{abstract}

Keywords: Personality, Self-efficacy, Performance, Medical student

Conflicts of Interest: None declared

Funding: Shiraz University of Medical Sciences (Grant No. 95-12938)

*This work has been published under CC BY-NC-SA 1.0 license.

Copyright $\odot$ Iran University of Medical Sciences

Cite this article as: Hayat AA, Kohoulat N, Amini M, Faghihi SAA. The predictive role of personality traits on academic performance of medical students: The mediating role of self-efficacy. Med J Islam Repub Iran. 2020 (11 Jul);34:77. https://doi.org/10.47176/mjiri.34.77

\section{Introduction}

One of the most important goals of students at all levels is to achieve good grades and to have a high level of academic success that has significant positive outcomes for both students and the community. Thus, one of the major preoccupations of educational systems and educational

\section{Corresponding author: Dr Seyed Ali Akbar Faghihi, faghihia@sums.ac.ir}

1. Clinical Education Research Center, Shiraz University of Medical Sciences, Shiraz, Iran 2. Department of Educational Psychology, Kharazmi University, Tehran, Iran psychologists is to identify the factors that influence students' academic performance (1-3). Students' academic performance is de pendent on a variety of factors not restricted to intelligence, teaching methods, gender, socioeconomic status, daily study hours, and study techniques (4-

$\uparrow$ What is "already known" in this topic:

In addition to educational variables, students' ability and intelligence, personality variables are seen as essential factors in students' performance in universities.

\section{$\rightarrow$ What this article adds:}

This study revealed that students with different personality traits have different performances at the university. In other words, some personality traits directly and indirectly, through selfefficacy, can affect students' academic performance. 
6). Accordingly, in the last decades, great attention has been paid to personal determinants of academic performance (7). Studies have shown that in addition to ability and intelligence, personality variables also have an important role in predicting academic performance (8). Researchers believed that among other factors, personality traits (conceptualized as Big Five trait theory) $(7,9-16)$ and self-efficacy beliefs (conceptualized as social cognitive theory) $(17,18)$ were significant predictors of academic performance. For example, the results of a meta-analysis showed that among the five factors, the strongest predictor for academic performance is conscientiousness. Other dimensions have shown smaller or no relationship with achievement (9). In other dimensions, occasionally, openness is a positive predictor and extraversion is a negative predictor of academic achievement $(8,19,20)$. However, many investigations consider conscientiousness as a robust predictor of achievement $(13,15,21,22)$.

In addition, studies showed that high levels of self-efficacy could directly and indirectly influence motivation and successful performance $(10,15,17,23,24)$. This concept is related to the individual's beliefs about their competence to do a specific duty and influences the cognitive and affective dimensions of the learning process (25). Some scholars believe that students who possess higher self-efficacy show superior performance and obtain better evaluation (26).

While the literature review shows that the relationship between self-efficacy and Big Five traits with performance is well-established, most studies have only examined the role of such predictors in the students' performance independently (24). Subsequently, they have led to a poor understanding of this relationship (15). Previous studies revealed that just focusing on the diversities between personality traits and self-efficacy may obstruct the integration of the theories that examine these factors (24). The operation levels of personality traits and self-efficacy are diverse. Whereas personality traits describe the person's intrinsic traits (27), self-efficacy characterizes a person's behavior regulated in confrontation to the environment (25). Accordingly, self-efficacy can permit intrinsic personality characters to be explicit as behavior, proposing a mediating role for self-efficacy. In this regard, some studies have shown that the association between personality traits and academic achievement may be mediated by students' self-efficacy $(24,28,29)$. For example, Giunta et al (2013) indicated that the role of conscientiousness in predicting students' achievement was completely mediated by self-efficacy (29). In general, in medical education, considering the effect of personality traits on performance based on Big Five traits and self-efficacy as a mediator variable is much lower than other areas. Some researchers believe that there are conflicting findings regarding the relationship between personality traits and academic performance in medical context (30). Therefore, this study aimed to determine if selfefficacy mediates the correlation between these factors and academic achievement in the context of medical sciences.

\section{Methods}

This was a quantitative cross sectional study. Participants were medical students at Shiraz University of Medical Sciences. Although for SEM, various rules-of-thumb have been introduced, a sample larger than 200 is acceptable; some also suggested 20 samples per variable $(31,32)$. However, in this study, to determine the sample size, we followed the instructions by Hair, Hult, Ringle, and Sarstedt (33), which are based on significance level, statistical power, and the number of independent variables. Since our model comprised 6 independent variables (openness, conscientiousness, extroversion, agreeableness, neuroticism, and self-efficacy) serving as predictors of the ultimate dependent variable (academic performance), the minimum sample size of 180 was required to secure a statistical power of $80 \%$ for detecting R2 values of at least 0.10 in any of the endogenous variables for the significant level of $5 \%$. Our sample size satisfied both views. Hence, 249 students, who were selected through convenience sampling, properly completed and returned the questionnaires. To collect data, we used 2 valid and reliable questionnaires.

\section{Big five inventory}

Big five inventory evaluates Big Five personality dimensions, including extraversion, neuroticism, openness, agreeableness, and conscientiousness (34). We used the Rammstedt and Johns' short version (10-item) personality traits questionnaire with 5 point Likert scale (strongly disagree to strongly agree) (35). The reliability and validity of the questionnaire were confirmed in Iran (36). In addition, we used the confirmatory factor analysis (CFA) to check the validity and reliability of BFI. First, we used Cronbach's alpha and composite reliability (CR) to test the internal consistency of Big Five Inventory, and the values were over the recommended criterion of 0.7 for all constructs (Table 1). Second, we applied the factor loadings and average variance extracted (AVE) to determine convergent validity. According to the results of confirmatory factor analysis, all the items yielded a loading higher than 0.7 on their corresponding construct with appropriate AVE, ranging from 0.76 to 0.87 . (0.55). Hence, the validity and reliability of the questionnaire was approved (Table 1).

\section{General Self-efficacy}

Another measurement was the New General Self-Efficacy Scale (GSE).

The GSE consists of 8 items developed and validated by Chen et al (2001) and consists of 8 items designed on Likert scale (5 point) (37). Some scholars reported positive psychometric evidence for this measure (37). The reliability and validity of this questionnaire was confirmed in Iran (38). In addition, to assess the internal consistency reliability of the GSE, we used composite reliability (CR) and Cronbach's alpha, and to determine convergent validity, we used average variance extracted (AVE) and factor loadings. According to the findings, Cronbach's alpha and composite reliability $(\mathrm{CR})$ were greater than 0.7 , and internal consistency was confirmed. Also, all the items indicated a loading higher than 0.7 on their corresponding construct with appropriate AVE (0.55). Hence, the validity and reliability of the GSE were achieved (Table 1). 


\begin{tabular}{|c|c|c|c|c|c|c|}
\hline Variables & Items & Loadings & $\mathrm{CR}$ & $\alpha$ & AVE & Convergent Validity \\
\hline Openness & Q5 & 0.91 & 0.90 & 0.80 & 0.83 & Confirmed \\
\hline Conscientiousness & $\begin{array}{l}\text { Q3 } \\
\text { Q3 } \\
\text { Q4 }\end{array}$ & $\begin{array}{l}0.90 \\
0.92 \\
0.94\end{array}$ & 0.93 & 0.86 & 0.87 & Confirmed \\
\hline Extraversion & $\begin{array}{c}\text { Q9 } \\
\text { Q10 }\end{array}$ & $\begin{array}{l}0.99 \\
0.85\end{array}$ & 0.92 & 0.90 & 0.86 & Confirmed \\
\hline Agreeableness & $\begin{array}{l}\text { Q7 } \\
\text { Q8 }\end{array}$ & $\begin{array}{l}0.90 \\
0.93\end{array}$ & 0.91 & 0.81 & 0.84 & Confirmed \\
\hline Neuroticism & $\begin{array}{l}\text { Q1 } \\
\text { Q2 }\end{array}$ & $\begin{array}{l}0.84 \\
0.90\end{array}$ & 0.86 & 0.69 & 0.76 & Confirmed \\
\hline & $\begin{array}{l}\text { Q11 } \\
\text { Q12 }\end{array}$ & $\begin{array}{l}0.72 \\
0.73\end{array}$ & 0.90 & 0.80 & 0.55 & Confirmed \\
\hline Self-efficacy & $\begin{array}{l}\text { Q13 } \\
\text { Q14 } \\
\text { Q16 } \\
\text { Q17 } \\
\text { Q18 } \\
\text { Q19 }\end{array}$ & $\begin{array}{l}0.74 \\
0.69 \\
0.75 \\
0.79 \\
0.78 \\
0.72\end{array}$ & & & & \\
\hline
\end{tabular}

\section{Academic performance}

The students' academic performance was measured by their total grade of previous terms.

\section{Statistical analysis}

We analyzed the data using SPSS18 (mean, SD, and Pearson correlation) and Smart-PLS 3.0, with a significance level of $p<0.05$. To analyze the relationship between the variables, Structural Equation Modeling (SEM) with Partial Least Squares (PLS) approach was applied. The popularity of PLS-SEM has been rapidly growing among scholars and in various disciplines (39). PLS-SEM involves a 2-stage process (Hair et al, 2014; Sarstedt et al, 2014; Henseler \& Fassott, 2010). The first stage involves evaluating the reliability and validity of the measures in the measurement models. The measurement model exhibits the relationships between the indicator/observable variables and their relevant constructs. In other words, we assessed the constructs through composite reliability and convergent and discriminant validity by several criteria. In the second stage, after checking the reliability and validity of the measurement, the researchers moved on to the assessment of the structural model to examine whether the hypotheses were confirmed. The structural model was evaluated by 3 necessary measures: R2; path coefficient, which should be statistically significant (path-analysis of bootstrapping); and Q2 (predictive relevance). (Hair et al, 2017; Hair et al, 2014; Sarstedt et al, 2014; Sarstedt, Ringle, Hair, 2017). Finally, to measure the overall model fit for PLS-SEM, we used the goodness-of-fit (GOF) as an index for validating the PLS model globally.

\section{Ethical considerations}

First, we obtained ethical approval from the Ethics Committee of Shiraz University of Medical Sciences; then, we acquired informed consent and asked the students to complete the anonymous questionnaires. We also assured them that their data would remain confidential and anonymous.

\section{Results}

The age range of participants was 18-32 years (mean 20.3, SD 2.4). Also, 163 (65.46\%) of participants were females and $86(34.53 \%)$ were males. The results showed that openness, conscientiousness, and agreeableness had a significant positive correlation with self-efficacy and academic performance $(p \leq 0.001)$. Moreover, self-efficacy had a significant positive relationship with academic performance $(\mathrm{p} \leq 0.001)$. Also, findings showed that neuroticism had a significant negative correlation with self-efficacy and academic performance $(\mathrm{p} \leq 0.001)$ (Table 2$)$.

\section{The measurement model}

According to the results of confirmatory factor analysis, all the items of construct showed loadings higher than 0.6 with acceptable AVE (AVE $\geq 0.5)$. Also, CR values were higher than 0.8 (Table 1 ).

The findings also showed that all intercorrelation values between the constructs were lower than the square roots of average variance extracted (AVE) (Table 3) and discriminant validity was confirmed. Therefore, the validity and reliability of the research constructs were confirmed.

\section{The structural model}

The results showed that all predicting variables possessed a VIF value lower than 0.3 , and their tolerance was higher than 0.2 ; therefore, there was no multiple collinearity. To test the causal relationship between personality traits, selfefficacy, and academic performance, we used the structural model assessment (Fig. 1).

Table 2. The Pearson correlation between self-efficacy, Big Five Personality Traits, and academic performance

\begin{tabular}{lcccccc}
\hline & Agreeableness & Conscientiousness & Openness & Extraversion & Neuroticism & Academic performance \\
\hline Self-efficacy & $0.43^{* *}$ & $0.60^{* *}$ & $0.66^{* *}$ & 0.001 & $-0.25^{* *}$ & $0.65^{* *}$ \\
Academic performance & $0.54^{* *}$ & $0.62^{* *}$ & $0.56^{* *}$ & 0.017 & $-0.34^{* *}$ & 1 \\
\hline$* *$ Significant correlation & & & & & &
\end{tabular}

**Significant correlation 
The role of personality traits and self-efficacy on academic performance

\begin{tabular}{|c|c|c|c|c|c|c|}
\hline Construct & Agreeableness & Conscientiousness & Extraversion & Neuroticism & Openness & Self-efficacy \\
\hline Agreeableness & 0.91 & & & & & \\
\hline Conscientiousness & 0.52 & 0.93 & & & & \\
\hline Extraversion & 0.02 & -0.04 & 0.92 & & & \\
\hline Neuroticism & -0.09 & -0.31 & 0.03 & 0.87 & & \\
\hline Openness & 0.47 & 0.45 & 0.11 & -0.17 & 0.91 & \\
\hline Self-efficacy & 0.44 & 0.62 & -0.01 & -0.34 & 0.67 & 0.74 \\
\hline
\end{tabular}

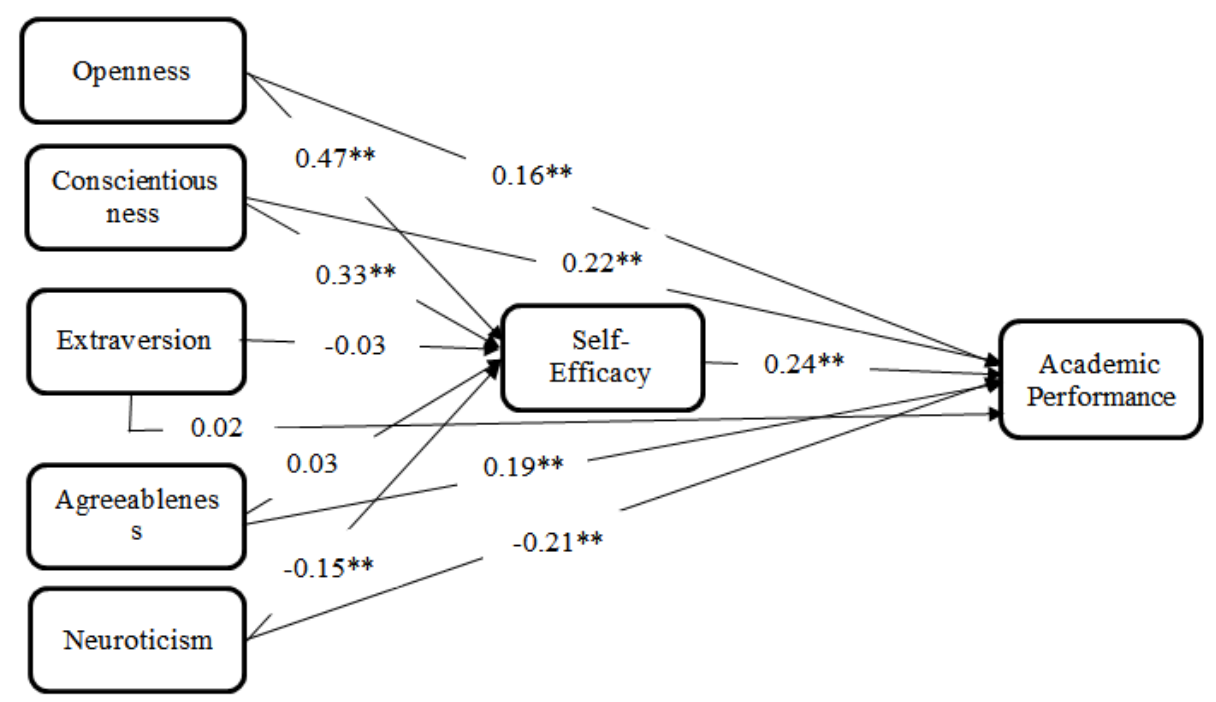

Fig. 1. PLS-Path Analysis

Based on the obtained results, openness $(\beta=0.16$, $\mathrm{p}<0.001)$, conscientiousness $(\beta=0.22, \mathrm{p}<0.001)$, agreeableness $(\beta=0.19, p<0.001)$, and self-efficacy $(\beta=0.24$, $\mathrm{p}<0.001)$ had a significant positive and direct effect on students' performance. Neuroticism $(\beta=-0.21, \mathrm{p}<0.001)$ had a negative, meaningful, and direct effect on students' performance. In addition, conscientiousness $(\beta=0.33, \mathrm{p}<0.001)$ and openness $(\beta=0.47, \mathrm{p}<0.001)$ had a significant positive and direct impact on self-efficacy (Table 1). Moreover, the Sobel test and mediation test indicated the positive and indirect effect of openness $(\beta=0.114, p<0.001)$ and conscientiousness $(\beta=0.081, \mathrm{p}<0.001)$ on students' performance through self-efficacy. Also, the results showed that neuroticism had a negative indirect effect on academic performance through self-efficacy $(\beta=-0.0361, p<0.001)$ (Fig. 1, Table 4).
Also, $57 \%$ of the variance in academic performance was explained by openness, conscientiousness, agreeableness, neuroticism, and self-efficacy. Furthermore, the findings revealed that openness, conscientiousness, and neuroticism explained $60 \%$ of the variance in self-efficacy. The predictive quality of the model was confirmed by obtained $\mathrm{Q}^{2}$ that ranged between 0.269 and 0.546 . The obtained GOF was 0.473 , which means the proposed model is globally fit.

\section{Discussion}

The research indicated the association among personality traits, self-efficacy, and academic achievement of medical students. The results showed that individual differences in personality traits, such as conscientiousness, openness, and agreeableness, played an essential function in contributing

\begin{tabular}{|c|c|c|c|c|c|}
\hline Hypotheses & Path & Direct effects & Indirect effects & Total effects & Decision \\
\hline & \multicolumn{5}{|c|}{ On academic performance via } \\
\hline $\mathrm{H}_{1}$ & Conscientiousness & 0.225 & 0.081 & 0.306 & Supported \\
\hline $\mathrm{H}_{2}$ & Openness & 0.164 & 0.114 & 0.279 & Supported \\
\hline $\mathrm{H}_{3}$ & Extraversion & 0.020 & -0.072 & 0.027 & Unsupported \\
\hline $\mathrm{H}_{4}$ & Neuroticism & -0.21 & -0.036 & -0.253 & Supported \\
\hline $\mathrm{H}_{5}$ & Agreeableness & 0.192 & 0.007 & 0.199 & Supported \\
\hline $\mathrm{H}_{6}$ & $\begin{array}{c}\text { On academic performance via } \\
\text { Self-efficacy } \\
\text { On self-efficacy via }\end{array}$ & 0.240 & --- & 0.240 & Supported \\
\hline $\mathrm{H}_{7}$ & Conscientiousness & 0.339 & --- & 0.339 & Supported \\
\hline $\mathrm{H}_{8}$ & Openness & 0.479 & --- & 0.479 & Supported \\
\hline $\mathrm{H}_{9}$ & Extraversion & -0.03 & --- & -0.03 & Unsupported \\
\hline $\mathrm{H}_{10}$ & Neuroticism & -0.15 & --- & -0.15 & Supported \\
\hline $\mathrm{H}_{11}$ & Agreeableness & 0.033 & --- & 0.033 & Unsupported \\
\hline
\end{tabular}


to students' academic success, in accordance with the literature $(8,9,13,21,24)$; also, conscientiousness was the most powerful predictor of academic achievement. This finding is in agreement with the results of previous studies $(15,40)$. This factor is related to goal-setting and sustained effort, both of which contribute to academic achievement (41), time management in learning, and effort regulation (42). In other words, conscientious persons are defined as achievement-oriented, industrious learners, and highly responsible. These specifications make the learners determined to obtain excellent academic achievement (43).

Our results about openness were in line with previous studies. The researchers stated that "Openness appears to reflect the ideal student," due to its relationship with resourceful, intelligent, and being foresighted. In the FiveFactor model, openness was positively associated with learning motivation approach to learning (44) and critical thinking (42) and was negatively correlated with absenteeism (40). Also, the results indicated that agreeableness had a positive correlation with students' performance. This result is in line with that of previous studies (45). These students with such characteristics trust others and have a great sense of cooperation. Therefore, they emphasize communication and collaboration with other students, which makes them more cooperative and collaborative in schooling. In addition, agreeableness helps the students to establish and maintain a suitable and beneficial relationship with their classmates and agreement with teacher instructions (45). Also, some believe that these individuals are good rational thinkers and can focus on the task at hand, which leads to better academic performance. In line with some previous studies (15), the results indicated a negative relationship between neuroticism and performance. Some researchers believe that this relationship can be related to anxiety features of neurotic personalities, and thus lower performance level (46). Also, the results showed that the self-efficacy of students could positively predict academic performance. This finding is in line with several previous studies $(10,15,17$, $24,29)$. In these studies, because of the impact on effort, persistence, goals, resourcefulness, and use of cognitive strategies, self-efficacy was the constant predictor of academic achievement (47-49). For example, Abouserie (1995) states that weak or strong levels of self-efficacy may be correlated with involvement with failure or success, and these relationships can characterize the performance of university students (50). Also, Frey and Determan (2004) believe that students with higher capability show higher achievement and obtain higher evaluations. These students have less anxiety and higher self-efficacy (26). In fact, researchers claim that high academic achievement could be linked with enhancement of confidence in people's potency and higher responsibility for successful completion of projects (51).

Based on the structural equation model (SEM) analyses, the association between personality traits (conscientiousness, openness, and neuroticism) and academic achievement was mediated by self-efficacy. Caprara et al (2011) claimed that a person who believes in him/herself transfers these fundamental dispositions into behavior (24). Therefore, self-efficacy can be considered as a contributor to the regulation and development of behaviors, which are identified as personality traits (48). Hence, self-efficacy may guide intrinsic characteristics of conscientiousness and openness (29) in preparing and performing the task at hand. An acceptable description for this proposition is that increased motivation, persistence and interest, which are associated with upper levels of self-efficacy (52), can produce fundamental characteristics of a person's conscientiousness and openness (eg, self-discipline and organization, ability to progress, intellectual curiosity (27), and ability to achieve higher levels of learning and performance). About the mediating role of self-efficacy between neuroticism and academic performance, the suitable explanation is that the learner who has anxiety and worry may have low academic self-concepts, which may result in discontinuation of learning.

When interpreting the results of this study, potential limitations must be considered. First, using self-reported questionnaires such as new general self-efficacy and Big Five Inventory may cause social desirability and method bias. To decrease this potential effect, we explained to the respondents that their information would only be used for study goals. Second, the generalizability of the results was limited to medical students at Shiraz University of Medical Sciences. Therefore, the study results should be confirmed using different samples and various cultural contexts.

\section{Conclusion}

The results of this study showed that students' personality traits, directly and indirectly, through self-efficacy, can affect their academic performance. These findings confirmed those of previous studies. Therefore, it can be concluded that students who have specific personality traits such as conscientiousness, openness, and agreeableness will have better performance in college.

\section{Implications}

As highlighted by researchers in recent years, attention to cognitive abilities for selecting students and predicting their performance in academic and clinical contexts is not sufficient; therefore, given the above-mentioned point and the results of the present study, it is suggested that medical schools use cognitive and noncognitive factors such as personality traits tests in their assessments. Moreover, considering the fact that counseling programs are performed in universities, the results of this study can be used by the counselors at universities. For example, personality tests can be used as an instrument for primary interventions to help the counselors detect those students at risk of academic failure. This helps the students receive the best counseling and educational services in their schooling. Moreover, the findings of this study will help medical school authorities to focus on the students' self-efficacy, which is of utmost importance. The results revealed that self-efficacy could serve as an effective mechanism in the association of personality traits and academic achievement. In addition to early detection of the students who are potentially at risk and performing interventions in this regard, an increase in students' self-efficacy can be a practical measure to change 
and improve the students' achievements. Personality traits are usually stable, while self-efficacy can be changed through appropriate interventions. Thus, there are various educational approaches that can be used to change self-efficacy status. First, since students' self-efficacy is affected by stressful and competitive contexts, a peaceful and supportive environment created by medical teachers can reduce students' stress. Also, medical teachers can stimulate positive emotions in students by using interactive techniques in classrooms, giving supportive, appropriate and positive feedback, and encouraging cooperation instead of competition.

Moreover, teaching quality can affect students' dominance and self-efficacy and thus impact students' achievement indirectly. Therefore, teaching quality and expression of emotions can affect students' learning, which can be an essential element for increasing students' self-efficacy.

\section{Acknowledgments}

We appreciate the Research Deputy of Shiraz University of Medical Sciences (SUMS) for funding this research (Grant No. 95-12938). Also, we wish to thank all medical students who participated in this study.

\section{Conflict of Interests}

The authors declare that they have no competing interests.

\section{References}

1. Artino AR, La Rochelle JS, Durning SJ. Second-year medical students' motivational beliefs, emotions, and achievement. Med Educ. 2010;44(12):1203-12.

2. Bergold S, Steinmayr R. Personality and intelligence interact in the prediction of academic achievement. J Intell. 2018;6(2):27.

3. Hayat AA, Jahanian M, Bazrafcan L, Shokrpour N. Prevalence of Academic Procrastination Among Medical Students and Its Relationship with Their Academic Achievement. Shiraz E Med J. April 2020:e96049.

4. Khan MS, Malik AR, Butt AUA, Khalid A, Maqbool S, Khan H, et al. Personality Dynamism and Academic Performance Among Boarders and Non-boarders Studying in a Medical University. Cureus. 2019;11(7).

5. Sagheb MM, Amini M, Saber M, Moghadami M, Nabiei P, Khalili R, et al. Teaching Evidence-Based Medicine (EBM) to Undergraduate Medical Students through Flipped Classroom Approach. Shiraz E Med J. 2018;19(2).

6. Rastegar Kazerooni A, Ghazanfari S, Hayat AA, Amini M. Guiding first-year medical students by outcome-based study guide during their medical education journey. Med Teach. 2019:15(1).

7. Robbins SB, Lauver K, Le H, Davis D, Langley R, Carlstrom A. Do psychosocial and study skill factors predict college outcomes? A metaanalysis. Psychol Bull. 2004;130(2):261.

8. O'Connor MC, Paunonen SV. Big Five personality predictors of postsecondary academic performance. Pers Individ Differ. 2007;43(5):97190.

9. Poropat AE. A meta-analysis of the five-factor model of personality and academic performance. Psychol Bull. 2009;135(2):322.

10. De Feyter T, Caers R, Vigna C, Berings D. Unraveling the impact of the Big Five personality traits on academic performance: The moderating and mediating effects of self-efficacy and academic motivation. Learn Individ Differ. 2012;22(4):439-48.

11. Chamorro-Premuzic T, Furnham A. Personality predicts academic performance: Evidence from two longitudinal university samples. J Res Pers. 2003;37(4):319-38.

12. Duff A, Boyle E, Dunleavy K, Ferguson J. The relationship between personality, approach to learning and academic performance. Pers Individ Differ. 2004;36(8):1907-20.
13. Komarraju M, Karau SJ, Schmeck RR. Role of the Big Five personality traits in predicting college students' academic motivation and achievement. Learn Individ Differ. 2009;19(1):47-52.

14. Komarraju M, Karau SJ, Schmeck RR, Avdic A. The Big Five personality traits, learning styles, and academic achievement. Pers Individ Differ. 2011;51(4):472-7.

15. Stajkovic AD, Bandura A, Locke EA, Lee D, Sergent K. Test of three conceptual models of influence of the big five personality traits and self-efficacy on academic performance: A meta-analytic path-analysis. Pers Individ Differ. 2018;120:238-45.

16. Brandt ND, Lechner CM, Tetzner J, Rammstedt B. Personality, cognitive ability, and academic performance: Differential associations across school subjects and school tracks. J Pers. 2019;88(2):249-265.

17. Caprara GV, Fida R, Vecchione M, Del Bove G, Vecchio GM, Barbaranelli C, et al. Longitudinal analysis of the role of perceived selfefficacy for self-regulated learning in academic continuance and achievement. J Educ Psychol. 2008;100(3):525.

18. Bandura A, Barbaranelli C, Caprara GV, Pastorelli C. Multifaceted impact of self-efficacy beliefs on academic functioning. Child Dev. 1996;67(3):1206-22.

19. DeYoung CG, Hirsh JB, Shane MS, Papademetris X, Rajeevan N, Gray JR. Testing predictions from personality neuroscience: Brain structure and the big five. Psychol Sci. 2010;21(6):820-8.

20. Noftle EE, Robins RW. Personality predictors of academic outcomes: big five correlates of GPA and SAT scores. J Pers Soc Psychol. 2007;93(1):116.

21. Laidra K, Pullmann H, Allik J. Personality and intelligence as predictors of academic achievement: A cross-sectional study from elementary to secondary school. Pers Individ Differ. 2007;42(3):44151 .

22. Conard MA. Aptitude is not enough: How personality and behavior predict academic performance. J Res Pers. 2006;40(3):339-46.

23. Köseoglu Y. Self-Efficacy and Academic Achievement--A Case from Turkey. J Educ Pract. 2015;6(29):131-41.

24. Caprara GV, Vecchione M, Alessandri G, Gerbino M, Barbaranelli C. The contribution of personality traits and self-efficacy beliefs to academic achievement: A longitudinal study. Br J Educ Psychol. 2011;81(1):78-96.

25. Bandura A. Self-efficacy: The exercise of control: Macmillan; 1997.

26. Frey MC, Detterman DK. Scholastic assessment or g? The relationship between the scholastic assessment test and general cognitive ability. Psychol Sci. 2004;15(6):373-8.

27. McCrae RR, Costa Jr PT. A five-factor theory of personality. Handbook of personality: Theory and Research. 1999;2(1999):139-53.

28. Tabak F, Nguyen N, Basuray T, Darrow W. Exploring the impact of personality on performance: How time-on-task moderates the mediation by self-efficacy. Pers Individ Differ. 2009;47(8):823-8.

29. Di Giunta L, Alessandri G, Gerbino M, Kanacri PL, Zuffiano A, Caprara GV. The determinants of scholastic achievement: The contribution of personality traits, self-esteem, and academic selfefficacy. Learn Individ Differ. 2013;27:102-8.

30. Sobowale K, Ham SA, Curlin FA, Yoon JD. Personality traits are associated with academic achievement in medical school: a nationally representative study. Acad Psychiatry. 2018;42(3):338-45.

31. Kline RB. Principles and practice of structural equation modeling: Guilford publications; 2015.

32. Violato C, Hecker KG. How to use structural equation modeling in medical education research: A brief guide. Teach Learn Med. 2007;19(4):362-71

33. Hair Jr JF, Hult GTM, Ringle C, Sarstedt M. A primer on partial least squares structural equation modeling (PLS-SEM): Sage publications; 2016.

34. John OP, Srivastava S. The Big Five trait taxonomy: History, measurement, and theoretical perspectives. Handbook of personality: Theory and research. 1999;2(1999):102-38.

35. Rammstedt B, John OP. Measuring personality in one minute or less: A 10-item short version of the Big Five Inventory in English and German. J Res Pers. 2007;41(1):203-12.

36. Mohammad Zadeh A, Najafi M. Validating of the Big Five Inventory (BFI-10): A very brief measure of the five factor personality model. Educ Measur. 2010;1(2):117-30.

37. Chen G, Gully SM, Eden D. Validation of a new general self-efficacy scale. Organ Res Methods. 2001;4(1):62-83.

38. Chegini Z, Janati A, Asghari-Jafarabadi M, Khosravizadeh O. Organizational commitment, job satisfaction, organizational justice and 
self-efficacy among nurses. Nurs Pract Tod. 2019; 6(2): 86-93.

39. Sarstedt M, Ringle CM, Hair JF. Partial least squares structural equation modeling. Handbook of market research. 2017:1-40.

40. Lounsbury JW, Steel RP, Loveland JM, Gibson LW. An investigation of personality traits in relation to adolescent school absenteeism. J Youth Adolesc. 2004;33(5):457-66.

41. Steel P. The nature of procrastination: A meta-analytic and theoretical review of quintessential self-regulatory failure. Psychol Bull. 2007;133(1):65.

42. Bidjerano T, Dai DY. The relationship between the big-five model of personality and self-regulated learning strategies. Learn Individ Differ. 2007;17(1):69-81.

43. Hakimi S, Hejazi E, Lavasani MG. The relationships between personality traits and students' academic achievement. Procedia Soc Behav Sci. 2011;29:836-45.

44. Vermetten YJ, Lodewijks HG, Vermunt JD. The role of personality traits and goal orientations in strategy use. Contemp Educ Psychol. 2001;26(2):149-70.

45. Nighute S, Sadawarte S. Relationship between big five personality traits and academic performance in medical students. J Evol Med Dent Sci. 2014;3(17).

46. Furnham A, Mitchell J. Personality, needs, social skills and academic achievement: A longitudinal study. Pers Individ Differ. 1991;12(10):1067-73.

47. Farsides T, Woodfield R. Individual differences and undergraduate academic success: The roles of personality, intelligence, and application. Pers Individ Differ. 2003;34(7):1225-43.

48. Bandura A. On the functional properties of perceived self-efficacy revisited. J Manage. 2012;38(1):9-44.

49. Klassen RM, Usher EL. Self-efficacy in educational settings: Recent research and emerging directions. The decade ahead: Theoretical perspectives on motivation and achievement: Emerald Group Publishing Limited; 2010. p. 1-33.

50. Abouserie R. Self-esteem and achievement motivation as determinants of students' approaches to studying. Stud High Educ. 1995;20(1):19-26.

51. Miller RB, Brickman SJ. A model of future-oriented motivation and self-regulation. Educ Psychol Rev. 2004;16(1):9-33.

52. Van Dinther M, Dochy F, Segers M. Factors affecting students' selfefficacy in higher education. Educ Res Rev. 2011;6(2):95-108. 